\title{
REAKTOR PENGOLAH AIR BERSIH IPTEK BAGI MASYARAKAT UNTUK DAERAH RAWAN BANJIR
}

\author{
Setyo Purwoto *)
}

\begin{abstract}
Abstrak
Air dari genangan banjir sebagai air baku diproses dengan model reactor kompak berupa 3 (tiga) kolom tabung dengan 7 treatment : filterisasi, kemudian dialirkan lewat kran untuk dikontakkan dengan PAC, lalu masuk pada adsorben Zeolit, dilanjutkan dengan exchange resin kation untuk mereduksi kation dari air, kemudian exchange diteruskan ke resin anion. Setelah keluar dari ion exchange, pembubuhan larutan kaporit diinjeksikan guna pembunuhan bakteri. Untuk menghilangkan bau, dilakukan absorbansi menggunakan $C A$.

Dari hasil treatment diperoleh kesimpulan bahwa : Pengolahan air banjir dengan model reactor kompak berupa 3 (tiga) kolom tabung dengan 7 treatment, yaitu : Filter, Poly Aluminium Chloride (PAC), Zeolit, Resin Kation, Resin Anion, Kaporit, dan Karbon Aktip (CA) mampu menurunkan parameter parameter: Warna 8.00 TCU, TDS 142.00 ppm, Kekeruhan 4.80 NTU, Kesadahan Total 586.50 ppm, Kalsium Hardness 305.00 ppm, Magnesium Hardness 51.80 ppm, Klorida 69.00 ppm, Alkalinity P 14.40 ppm, Alkalinity M 194.00 ppm, e-Coli 3.00 sat/100 ml.
\end{abstract}

Kata Kunci : Air Banjir, Zeolit, Ion Exchange, Air Jernih

\section{PENDAHULUAN \\ Latar Belakang}

Masyarakat di daerah rawan banjir mengalami kesulitan dalam hal kebutuhan air bersih, apalagi sebagai air minum. Hal ini disebabkan oleh tertutupnya seluruh sumber air, terutama air sumur gali. Peta rawan banjir di Provinsi Jawa Timur yang dihasilkan dari analisis sistem informasi geografis (SIG) berdasarkan variable variabel : penggunaan lahan, topografi/kemiringan lereng, jenis tanah dan jenis batuan, digolongkan menurut 5 klas. Kelas rawan banjir yang dimaksud adalah sangat rawan, rawan, cukup rawan, agak rawan dan tidak rawan. Tingkat rawan banjir dalam klas sangat rawan dan rawan berturutturut sebesar $6,95 \%$ dan $24,52 \%$.

Lokasi tingkat rawan banjir yang termasuk dalam klas sangat rawan terdistribusi di Kabupaten : Gresik, Bojonegoro, Lamongan, Surabaya, Sidoarjo, Ngawi, Madiun, Nganjuk, Tulungagung, dan Jombang. Peta tingkat rawan banjir yang telah dihasilkan dari hasil analisis system informasi geografis (SIG) tersebut merupakan data permanent. (Haryani, 2006)

Banjir akibat meluapnya Kali Lamong yang yang menyebabkan terendamnya ribuan rumah warga di Kecamatan Benjeng, Kabupaten Gresik, Jawa Timur, merupakan bencana rutin tahunan yang membuat masyarakat resah. Ironisnya, masyarakat tetap memilih bertahan di lokasi banjir walaupun genangan mencapai ketinggian $80 \mathrm{~cm}$ (bahkan lebih). Lebih kacau lagi, karakter banjir di daerah ini bisa datang ketika tidak ada hujan di daerah itu. Hal ini terjadi akibat tingginya cu- rah hujan di bagian hulu kali Lamong, namun luapannya melanda daerah Benjeng. Rentang waktu datangnya banjir cukup lama, yaitu sejak bulan Nopember hingga Maret, dengan durasi sekitar 4 hari genangan tiap banjir dengan frekuensi dalam satu bulan bisa dua, bahkan tiga kali kejadian. Dari 23 Desa di wilayah kecamatan Benjeng, terdapat 14 wilayah Desa yang merupakan langganan banjir, baik kiriman maupun luapan saat hujan tiba. Empat Desa yang paling parah adalah : Kedung Rukem, Sirnoboyo, Delik Sumber, dan Sedapur Klagen, dengan kondisi rumah terendam berturut turut sebanyak : 415, 325, 205, dan 139 dengan ketinggian rata rata antara 50 - $80 \mathrm{~cm}$ (Camat Benjeng - Gresik, Pebruari 2009)

Mengacu dari data di atas, maka penerapan IPTEKS ini dilakukan di Desa Kedung Rukem yang merupakan area paling parah terkena dampak banjir, baik dari jumlah rumah terendam maupun ketinggiannya. Teknologi yang diterapkan adalah : REAKTOR PENGOLAH AIR BERSIH UNTUK DAERAH RAWAN BANJIR

\section{Perumusan Masalah}

Rumusan masalah dalam penerapan IPTEKS ini adalah :

Mengatasi krisis air bersih dan air minum bagi masyarakat terdampak banjir dengan menggunakan teknologi tepat guna (TTG) berupa alat pengolah air dengan treatment : filterisasi, PAC terpadukan dengan Zeolit \& 

dalam sebuah reaktor kompak yang mudah dilakukan dalam keadaan banjir

Definisi :

\begin{tabular}{lll}
\hline $\begin{array}{l}\text { Filterisasi } \\
\text { Poly Aluminium }\end{array}$ & $:$ & $\begin{array}{l}\text { merupakan proses pemisahan antara padatan atau koloid dengan cairan } \\
\text { Chloride (PAC) }\end{array}$ \\
Zeolit & $: \begin{array}{l}\text { adah bahan kimia berbentuk cairan bening kekuningan yang berfungsi } \\
\text { merupakan kristal alumina silika yang berstruktur tiga dimensi yang dapat } \\
\text { dimanfaatkan untuk : filter, adsorben, ion-exchange, serta penurunan } \\
\text { kesadahan dalam air. }\end{array}$ \\
Karbon Aktip (CA) & $: \begin{array}{l}\text { merupakan arang dari bahan alami yang diaktipkan dan dapat berfungsi } \\
\text { sebagai adsorban untuk : zat organik, bau, rasa, serta polutan mikro } \\
\text { lainnya }\end{array}$ \\
Resin sintetis & $: \begin{array}{l}\text { Bahan kimia dengan gugus fungsional organik tertentu yang dapat ber- } \\
\text { fungsi sebagai penukar ion (lon-Exchanger) antara kation-anion dalam } \\
\text { resin dengan anion-kation yang terdapat pada larutan yang diperlakukan. }\end{array}$ \\
Kaporit & $: \begin{array}{l}\text { Zat kimia dengan komposisi kandungan OCl - yang berfungsi sebagai } \\
\text { desinfektan dalam penjernihan air }\end{array}$ \\
\hline
\end{tabular}

Asumsi :

1) Pengoperasian teknologi tepat guna (TTG) ini telah disesuaikan dengan kondisi dan situasi saat banjir, sehingga dapat diasumsikan bahwa masyarakat awam dapat dengan mudah untuk melakukannya. Disamping itu, pembuatannyapun tidaklah sulit, serta bahan baku cukup dari air genangan banjir di sekitar tempat tinggal.

2) Dengan adanya TTG pengolahan air bersih sebagaimana penerapan IPTEKS ini, masyarakat terdampak banjir dapat memperoleh air bersih untuk memenuhi kebutuhannya.

Lingkup penerapan IPTEKS : Desa Kedung Rukem Kecamatan Benjeng Kabupaten Gresik provinsi JATIM yang merupakan Desa rawan banjir terparah di daerah itu (2009).

\section{Teknologi Penerapan IPTEKS}

Teknologi IPTEKS dalam penerapan ini merupakan teknologi tepat guna (TTG) berupa alat pengolah air dengan treatment : filterisasi, PAC terpadukan dengan Zeolit \& karbon aktip (CA), Resin Sintetis, dan Kaporit dengan fungsi masing masing sebagai : penyaringan, sedimentasi, absorban, penukar ion, dan desinfektan. Alat ini dirangkai dalam sebuah reaktor kompak yang mudah dilakukan dalam keadaan banjir tanpa menggunakan listrik, tidak memerlukan pompa, dan mudah dalam hal pengoperasian serta penempatannya. Sedangkan bahan baku yang digunakan adalah air genangan banjir

\section{Tujuan Kegiatan IbM}

Tujuan dari pada penerapan IPTEKS (IbM) ini adalah :

Memberi pengetahuan serta pelatihan
tentang cara pengoperasian (penggunaan) alat pengolah air bersih (minum) sebagaimana rancangan reaktor dalam penerapan IPTEKS ini untuk digunakan pada saat darurat banjir. Mengingat pada saat banjir jaringan listrik padam dan ketersediaan pompa sangat sulit, maka rangkaian alat ini telah diseting untuk tidak menggunakan aliran listrik, juga tanpa memerlukan pompa, namun produk air hasil pengolahan tetap optimal.

b. Melatih warga masyarakat yang tempat tinggalnya rawan banjir untuk merakit sendiri teknologi tepat guna (TTG) tentang pengolah air minum dengan treatment ; filter, PAC yang dipadukan dengan Zeolit , Resin Sintetis, dan Kaporit, dan karbon aktip (CA) yang kompak dalam sebuah reaktor sederhana.

\section{Manfaat Kegiatan}

Manfaat dari penerapan IPTEKS ini adalah :

1) Untuk membantu mengatasi krisis air bersih dan air minum bagi masyarakat terdampak banjir.

2) Warga masyarakat langganan banjir mampu membuat sendiri alat rangkaian pengolah air bersih sebagaimana penerapan IPTEKS ini.

\section{BAHAN DAN METODE PENERAPAN IPTEKS (IbM)}

Penerapan IPTEKS (IbM) ini merupakan aplikasi perpaduan dari hasil penelitian dan pengabdian penulis, yaitu :

1) Desalinasi Air Payau Secara Ion Exchange dengan Treatment Resin Sintetis. (PDM-SPPH No.: 207/SP2H/ DP2M/III/2007) 
2) Removal Salinitas Air Payau Secara Ion Exchange dengan Treatment Resin Sintetis Pada Reaktor UpFlow-DownFlow (PDM-DIPA Nomor : 0145.0/023-04.0//2008),

3) Pengembangan Reaktor Demineralisasi Air Berbasis Resin Penukar Ion Terpadukan Dengan Membran Elektrodialisis Konduktif Bersekat (Hibah Bersaing ; APHB/2008/07248/002),

4) Optimasi Dosis Kaporit Sebagai Desinfektan Air Sumur (LPPM-UNIPA/ Pen. Dos/2006).

5) Filtrasi pada Instalasi Pengolahan Air (IPA) Untuk Meningkatkan Kualitas Produksi Air Bersih Di Desa Karanggeneng Kabupaten Lamongan - JA-

\section{TIM (Program}

No.ID;VO/07/26/001)

6) Aplikasi Teknologi Filtrasi Menuju Desa Mandiri Air Bersih di Karanggeneng Lamongan (KKN PPM ; 2056/P1/LPPMUGM/2008 Tgl. 2 April 2008)

Temuan hasil penelitian dan pengalaman dari pengabdian pada masyarakat tersebut diaplikasikan dalam penerapan IPTEKS sebagai model reactor kompak berupa 3 (tiga) kolom tabung dengan 7 treatment, yaitu : Filter, Poly Aluminium Chloride (PAC), Zeolit, Resin Kation, Resin Anion, Kaporit, dan Karbon Aktip (CA).

Skema reactor dimaksud digambarkan sebagai berikut :

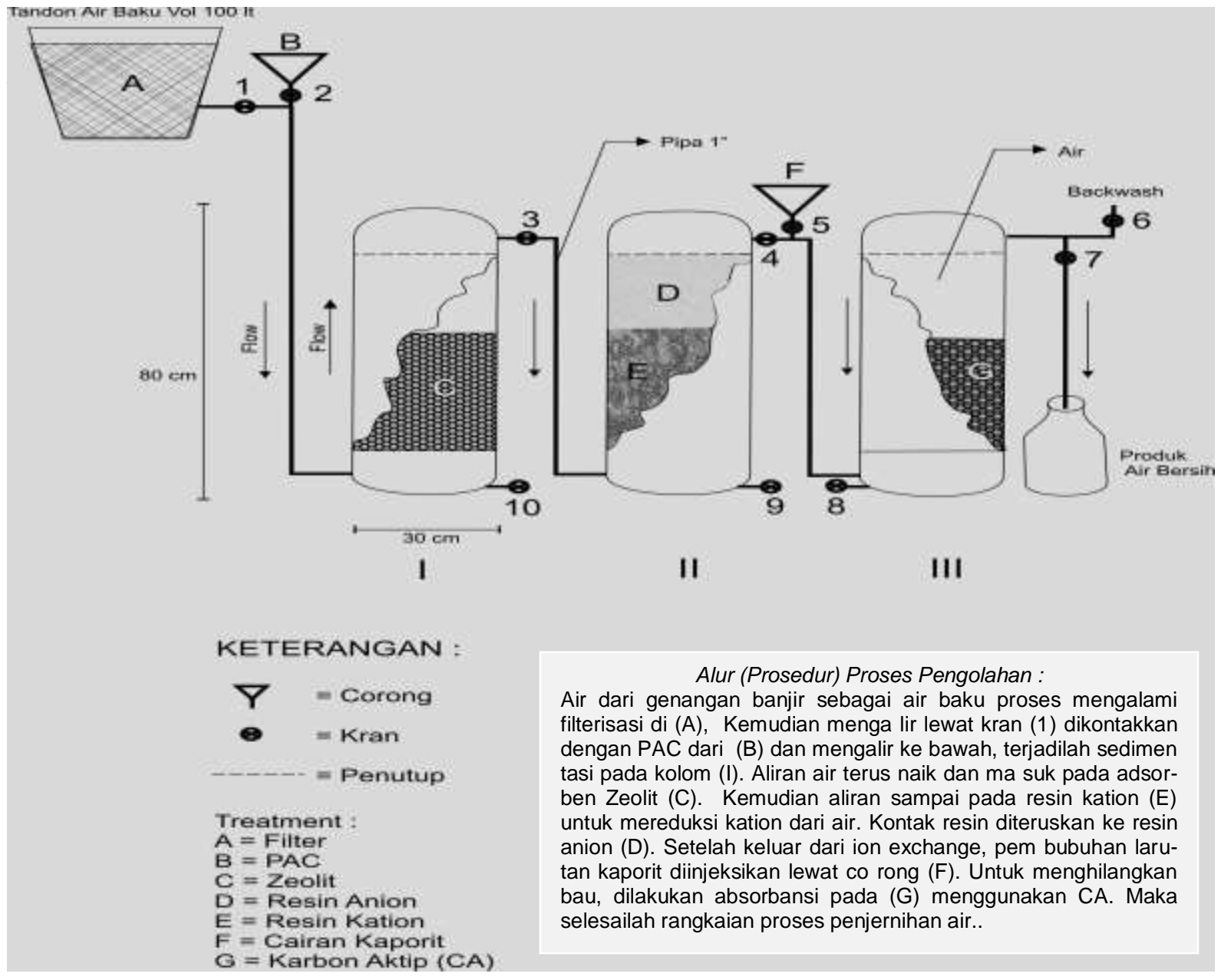

Gambar 1. Skema Reaktor Pengolah Air Minum Untuk Daerah Rawan Banjir 
Tabel 1. Spesifikasi Bahan Treatment Yang Digunakan dalam Penerapan IPTEKS

\begin{tabular}{|c|c|c|c|}
\hline No. & Treatment & Fungsi & Keterangan \\
\hline $\bar{A}$ & Filter & $\begin{array}{l}\text { pemisahan antara padatan } \\
\text { atau koloid dengan cairan }\end{array}$ & Filter busa diberi alas kain fittin \\
\hline B & $\begin{array}{l}\text { Poly Alumini } \\
\text { um Chloride } \\
\text { (PAC) }\end{array}$ & Sedimentasi , koagulasi & $\begin{array}{l}\text { Cairan bening kekuningan } \\
\text { Dosis : } 30-80 \mathrm{ppm} \\
\mathrm{pH}: 3,5\end{array}$ \\
\hline C & Zeolit & $\begin{array}{l}\text { Absorbsi, filterisasi, ion } \\
\text { exchange, pelunakan }\end{array}$ & $\begin{array}{l}\text { Ketebalan } 50 \mathrm{~cm} \\
\text { Ukuran Volume pori : } 0,5 \mathrm{~cm} 3 \\
\text { tiap } \mathrm{cm} 3 \text { volume zeolit. } \\
\text { Densitas antara } 2,0-2,3 \mathrm{~g} / \mathrm{cm} 3\end{array}$ \\
\hline D & Resin anion & $\begin{array}{l}\text { Penukar anion (penurunan } \\
\text { kation dalam air) }\end{array}$ & $\begin{array}{l}\text { Ketebalan } 30 \mathrm{~cm} \\
\text { Lewatit MonoPlus M } 500\end{array}$ \\
\hline$E$ & Resin kation & $\begin{array}{l}\text { Penukar kation (penurunan } \\
\text { anion dalam air) }\end{array}$ & $\begin{array}{l}\text { Ketebalan } 30 \mathrm{~cm} \\
\text { Dowex HCR-S }\end{array}$ \\
\hline $\mathrm{F}$ & Kaporit & $\begin{array}{l}\text { Desinfektan (Membunuh } \\
\text { Mikro Organisme) }\end{array}$ & $\begin{array}{l}\text { Dosis : } 1,5 \text { liter kaporit kadar } 1 \\
\text { gr/l per } 100 \text { liter air baku }\end{array}$ \\
\hline G & $\begin{array}{l}\text { Karbon } \\
\text { (CA) }\end{array}$ & $\begin{array}{l}\text { Adsorban untuk : zat organik, } \\
\text { bau, rasa, serta polutan mikro } \\
\text { lainnya }\end{array}$ & $\begin{array}{l}\text { Ukuran Mesh : } 8 \times 30, \text { s/d } 12 \times 50 \\
\text { Persentase ukuran : } 90 \% \\
\text { Bulk Density : } 0,50-0,55 \mathrm{~g} / \mathrm{ml} \\
\text { lodine number : } 800-900 \mathrm{mg} / \mathrm{g} \\
\mathrm{pH}: 9-11\end{array}$ \\
\hline
\end{tabular}

Tabel 2. Alasan Dipilihnya Bahan Treatment Dalam Penerapan IPTEKS

\begin{tabular}{|c|c|c|}
\hline No & Treatment & Alasan pemilihan \\
\hline $\bar{A}$ & $\begin{array}{l}\text { Filter busa diberi } \\
\text { alas kain fittin }\end{array}$ & $\begin{array}{l}\text { Praktis, murah, mudah didapat, mudah dicuci, kemampuan filter tinggi, } \\
\text { mudah dibentuk. }\end{array}$ \\
\hline B & $\begin{array}{l}\text { Poly Alumini } \\
\text { um Chloride } \\
\text { (PAC) }\end{array}$ & $\begin{array}{l}\text { Karena bentuknya cairan, maka akan lebih praktis dibanding dengan } \\
\text { Tawas, sedangkan kemampuan (daya) sedimentasi tidak jauh } \\
\text { berbeda. }\end{array}$ \\
\hline C & Zeolit & $\begin{array}{l}\text { - Bebas lumpur dan endapan } \\
\text { - Biaya cukup murah } \\
\text { - Sebas dari bahan kimia berbahaya dalam pengoperasian } \\
\text { - Dapat menghasilkan air hingga zero kesadahan }\end{array}$ \\
\hline D & $\begin{array}{l}\text { Resin anion } \\
\text { (Lewatit Mono } \\
\text { Plus } M \text { 500) }\end{array}$ & $\begin{array}{l}\text { - Secara spesifik dapat melakukan penukaran anion dari air. } \\
\text { - Lebih mudah dijumpai di pasaran. }\end{array}$ \\
\hline $\mathrm{E}$ & $\begin{array}{l}\text { Resin kation } \\
\text { Dowex HCR-S }\end{array}$ & $\begin{array}{l}\text { Secara spesifik dapat melakukan penukaran kation dari air. } \\
\text { Lebih mudah dijumpai di pasaran. }\end{array}$ \\
\hline $\mathrm{F}$ & Kaporit & $\begin{array}{ll}\checkmark & \text { Daya bunuh terhadap mikroorganisme cukup tinggi } \\
\checkmark & \text { Harga lebih terjangkau } \\
\checkmark & \text { Mudah didapat dibanding desinfektan yang lainnya } \\
\checkmark & \text { Penggunaan yang mudah } \\
\text { Tidak memerlukan listrik }\end{array}$ \\
\hline $\mathrm{G}$ & $\begin{array}{l}\text { Karbon Aktip } \\
\text { (CA) berbentuk } \\
\text { granular }\end{array}$ & $\begin{array}{l}\text { Pengoperasiannya mudah, karena air mengalir dalam media. } \\
\text { Proses perjalanan cepat, karena lumpur menggerombol. } \\
\text { Media tidak bercampur dengan lumpur sehingga dapat di regenerasi }\end{array}$ \\
\hline
\end{tabular}


Menurut McGarvey (1986), Control ketepatan aliran serta masalah kesetimbangan massa berdasar pada proses penukaran ion, tetapi penekanannya pada proses pereaksiannya, yaitu system batch ataukah continuous. Resin sebagai ion exchange memang diakui sebagai desalinasi konvensional untuk air payau atau air laut, sekalipun dilakukan secara pabrikasi.

\section{Perhitungan Volume Resin}

Berdasarkan perhitungan kapasitas operasi yang berpedoman pada koefisien selektifitas, maka volume resin yang dibutuhkan dapat diturunkan dari persamaan berikut :

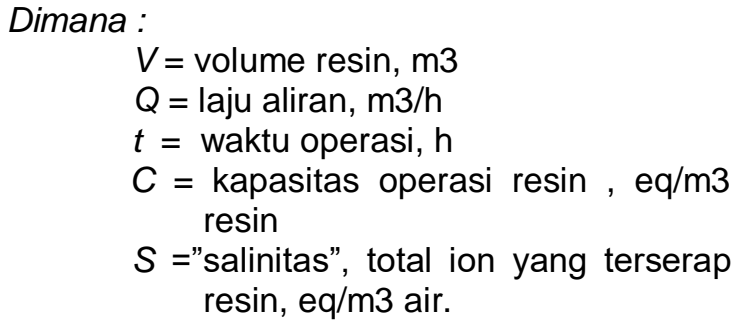

\begin{tabular}{|c|c|c|c|c|c|}
\hline $\begin{array}{l}\text { Tipe } \\
\text { Resin }\end{array}$ & Grup fungsional & $\begin{array}{l}\text { Kerapatan } \\
\text { Kering } \\
\left(\mathrm{Kg} / \mathrm{m}^{3}\right)\end{array}$ & $\begin{array}{l}\mathrm{pH} \\
\text { operasi }\end{array}$ & $\begin{array}{l}\text { Kapasitas } \\
(\mathrm{me} / \mathrm{ml})\end{array}$ & Contoh merk resin \\
\hline Asam kuat & $-\mathrm{SO}_{3}-\mathrm{H}^{+}$ & $790-850$ & $0-14$ & 2,0 & $\begin{array}{l}\text { Duolite C-20 } \\
\text { Amberlite } 120 \\
\text { Dowex } 50\end{array}$ \\
\hline Asam lemah & $-\mathrm{COO}^{-} \mathrm{H}^{+}$ & 720 & $7-14$ & 4,5 & $\begin{array}{l}\text { Duolite C-433 } \\
\text { Amberlite IRC-50 } \\
\text { Zeo Carb } 226\end{array}$ \\
\hline Basa kuat tipe I & $-\mathrm{CH}_{2} \mathrm{~N}\left(\mathrm{CH}_{3}\right)_{3} \mathrm{OH}^{-}$ & 720 & $0-14$ & 1,3 & $\begin{array}{l}\text { AmberlitelRA-410 } \\
\text { Duolite A-101 D }\end{array}$ \\
\hline Basa kua tipe II & $\begin{array}{l}-\mathrm{CH}_{2} \mathrm{~N}\left(\mathrm{CH}_{3}\right)_{2} \mathrm{CH}_{2} \\
\mathrm{CH}_{2} \mathrm{OH}^{+} \mathrm{OH}^{-}\end{array}$ & 720 & $0-14$ & 1,4 & $\begin{array}{l}\text { Amberlite IRA-140 } \\
\text { Duolite A-102 D }\end{array}$ \\
\hline Basa lemah & $-\mathrm{N}\left(\mathrm{CH}_{3}\right)_{2} \mathrm{H}^{+} \mathrm{OH}^{-}$ & 510 & $0-6$ & 2,5 & $\begin{array}{l}\text { Duolite A-7 } \\
\text { Amberlite IRA-93 }\end{array}$ \\
\hline
\end{tabular}

Selanjutnya kapasitas ion exchange biasanya dinyatakan dengan kapasitas total atau kapasitas operasi menurut formulasi berikut :

$$
X=\frac{C_{o} V_{o p}}{V_{r}}-\frac{C_{o}}{V_{r}} \sum_{i=1}^{n}\left(Y_{i} V_{i}\right)
$$

$$
V=(Q \cdot t \cdot S) / C
$$

Tabel 3. Tipe Resin Penukar Ion Sintetik

Sumber : (Sanks, 1982)

Menurut Mangum (2003), membran permeabel dapat meningkatkan keberhasilan removal salinitas dengan cara: a). Keluarnya kation yang terdapat pada air melewati membran permeabel kation, b). Keluarnya anion yang ada pada air melewati membran permeabel anion.

\section{HASIL DAN PEMBAHASAN}

Proses pengolahan air bersih dalam reaktor dilakukan sebagaimana alur berikut (lihat Gambar 1.) ; Air dari genangan banjir sebagai air baku proses mengalami filterisasi di (A), Kemudian menga lir lewat kran (1) dikontakkan dengan PAC dari (B) dan mengalir ke bawah, terjadilah sedimen tasi pada kolom (I). Aliran air terus naik dan ma suk pada adsorben Zeolit (C). Kemudian aliran sampai pada resin kation (E) untuk mereduksi kation dari air. Kontak resin diteruskan ke resin anion (D). Setelah keluar dari ion exchange, pem bubuhan larutan kaporit diinjeksikan lewat corong $(F)$. Untuk menghilangkan bau, dilakukan absorbansi pada $(G)$ menggunakan CA. Maka selesailah rangkaian proses penjernihan air..

Hasil analisis parameter disajikan pada Tabel 4. 
Tabel 4. Uji Analisis Parameter Hasil Treatment

\begin{tabular}{|c|c|c|c|c|}
\hline No & Parameter & Satuan & Sebelum treatment & Setelah treatment \\
\hline 1. & Suhu & $\mathrm{C}$ & 27 & 28 \\
\hline 2. & Warna & TCU & 12 & 4 \\
\hline 3. & TDS & $\mathrm{mg} / \mathrm{L}$ & 423 & 281 \\
\hline 4. & $\mathrm{DHL}$ & $\mu \mathrm{s} / \mathrm{cm}$ & 605 & 494 \\
\hline 5. & Kekeruhan & NTU & 6 & 1,2 \\
\hline 6. & $\mathrm{pH}$ & --- & 8,7 & 7,46 \\
\hline 7. & Besi & $\mathrm{mg} / \mathrm{L}$ & 0,9 & 0,3 \\
\hline 8. & Mangan & $\mathrm{mg} / \mathrm{L}$ & 0,4 & 0,2 \\
\hline 9. & Seng & $\mathrm{mg} / \mathrm{L}$ & 0,3 & 0,1 \\
\hline 10. & Natrium & $\mathrm{mg} / \mathrm{L}$ & 20,3 & 3,68 \\
\hline 11. & Kalium & $\mathrm{mg} / \mathrm{L}$ & 7,11 & 3,83 \\
\hline 12. & Silica & $\mathrm{mg} / \mathrm{L}$ & 31,2 & 12 \\
\hline 13. & Kesadahan Total & $\mathrm{mg} / \mathrm{L} \mathrm{CaCO} 3$ & 657 & 70,5 \\
\hline 14. & Kalsium Hardness & $\mathrm{mg} / \mathrm{L} \mathrm{CaCO} 3$ & 365 & 60 \\
\hline 15. & Magnesium Hardness & $\mathrm{mg} / \mathrm{L} \mathrm{CaCO} 3$ & 84,2 & 32,4 \\
\hline 16. & Klorida & $\mathrm{mg} / \mathrm{L}$ & 89 & 20 \\
\hline 17. & Nitrat \& nitrit sebagai $\mathrm{N}$ & $\mathrm{mg} / \mathrm{L}$ & 1,37 & 0,13 \\
\hline 18. & Alkalinity $\mathrm{P}$ & $\mathrm{mg} / \mathrm{L} \mathrm{CaCO} 3$ & 20 & 5,6 \\
\hline 19. & Alkalinity M & $\mathrm{mg} / \mathrm{L} \mathrm{CaCO} 3$ & 250 & 56 \\
\hline 20. & Sulfat & $\mathrm{mg} / \mathrm{L}$ & 67,8 & 34,7 \\
\hline 21. & e-Coli & $\mathrm{Sat} / 100 \mathrm{ml}$ & 4 & 1 \\
\hline
\end{tabular}

Tabel 5. Tinjauan Parameter Utama Hasil Treatment

\begin{tabular}{lll}
\hline Parameter & $\begin{array}{l}\text { Sebelum } \\
\text { treatment }\end{array}$ & $\begin{array}{l}\text { Setelah } \\
\text { treatment }\end{array}$ \\
\hline Warna & 12 & 4 \\
TDS & 423 & 281 \\
Kekeruhan & 6 & 1.2 \\
Kesadahan Total & 657 & 70.5 \\
Kalsium Hardness & 365 & 60 \\
Magnesium Hardness & 84.2 & 32.4 \\
Klorida & 89 & 20 \\
Alkalinity P & 20 & 5.6 \\
Alkalinity M & 250 & 56 \\
e-Coli & 4 & 1 \\
\hline
\end{tabular}

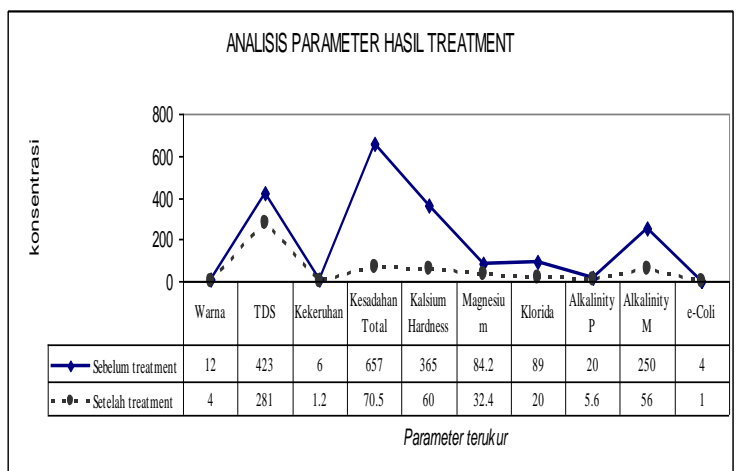

Gambar 2. Grafik Analisis Parameter Hasil Treatment Reaktor

Dari data hasil uji parameter air baku oleh pengaruh treatment, baik kekeruhan, kesadahan, warna, kation anion banyak yang mengalami penurunan yang signifikan.

Tabel 6. Removal Parameter Utama Hasil Treatment

\begin{tabular}{lrr}
\hline parameter & removal & $\begin{array}{c}\text { \% } \\
\text { moval }\end{array}$ \\
\hline Warna & 8.00 & 66.67 \\
TDS & 142.00 & 33.57 \\
Kekeruhan & 4.80 & 80.00 \\
Kesadahan Total & 586.50 & 89.27 \\
Kalsium Hardness & 305.00 & 83.56 \\
Magnesium Hardness & 51.80 & 61.52 \\
Klorida & 69.00 & 77.53 \\
Alkalinity P & 14.40 & 72.00 \\
Alkalinity M & 194.00 & 77.60 \\
e-Coli & 3.00 & 75.00 \\
\hline
\end{tabular}

\section{SIMPULAN}

Pengolahan air banjir dengan model reactor kompak berupa 3 (tiga) kolom tabung dengan 7 treatment, yaitu : Filter, Poly Aluminium Chloride (PAC), Zeolit, Resin Kation, Resin Anion, Kaporit, dan Karbon Aktip (CA) mampu menurunkan parameter parameter : Warna 8.00 TCU, TDS 142.00 ppm, Kekeruhan 4.80 NTU, Kesadahan Total 586.50 ppm, Kalsium Hardness 305.00 ppm, Magnesium Hardness 51.80 ppm, Klorida 69.00 ppm, Alkalinity P 14.40 ppm, Alkalinity M $194.00 \mathrm{ppm}$, e-Coli $3.00 \mathrm{sat} / 100 \mathrm{ml}$. 


\section{DAFTAR PUSTAKA}

Atastina S.B, Praswasti P.D.K. Wulan, dan Syarifudin. Penghilangan Kesadahan Air Yang Mengandung Ion Ca2+ Dengan Menggunakan Zeolit Alam Lampung Sebagai Penukar Kation diunduh dari dari "http://id.wikipedia.org/wiki/Zeolit"

Baruth, E.E., (2005). Water Treatment Plant Design. McGraw-Hill Publishing, Toronto.

Camat Benjeng - Gresik. Pebruari 2009. Data Dampak Banjir Januari 2009 (update data Pebruari 2009).

Haryani, N.S., Yulianto, F., Mannopo, A.K.S., (2006). Analisis Tingkat Rawan Banjir di Propinsi Jawa Timur Dari Data Penginderaan Jauh dan SIG.

Kusnaedi. 1995. Mengolah Air Gambut dan Air Kotor untuk Air Minum. Jakarta:Penebar Swadaya.)

Linsley R.K. dan Franzini J. 1991. Teknik Sumber Daya Air. Jakarta: Erlangga

Lee, G.C., and Foutch, G.L, (1997). An Evaluaion of Mass-transfer Coefficients for New and Used lon Exchange Resin. Reacive and Funcional Polymer.

Volume 35, issues 1-2. pp. 55-57

Mangum, W., (2003). Applications and Issues for Water Treatment Professionals. Volume 26, Issue 7 - July 2003

McGarvey, F.X., Fisher, S.A. (1986, August). Chapter 2.8 Measurements and control in ion exchange installations. Desalination Volume 59, Pages 403-424 online 17 September 2002. Dipungut 27 Juli 2008.

Montgomery, J. M. (1985) Water Treatment Principles and Design. A Wiley-Interscience Publishing, Singapore.

Reynold, R. (1982). Unit operation and processes in environmental engineering. Australia

Saifudin, R., Astuti, D., (2005). Jurnal Penelitian Sains \& Teknologi, Volume. 6, No. 1,: 49 - 64.

Said N.I. 1999. Kesehatan Masyarakat dan Teknologi Peningkatan Kualitas Air.Direktorat Teknologi Lingkungan.

Sanks, R. L. (1982) Water Treatment Plant Design. Butterworths, England.

Sharples, P.M., Bolto, B.A. (1997). Desalination. Desalting in Australia : The development of a new Process for Brackhis Water. Volume 20, issues 1-3 March 1977 pages : 391-401

Tjokrokusumo. 1995Pengantar Konsep Teknologi Bersih Khusus Pengelolaan dan Pengolahan Air. Yogyakarta: STTL YLH. 